American Journal of Applied Sciences 9 (3): 372-375, 2012

ISSN 1546-9239

(C) 2012 Science Publications

\title{
Interfragmentary Modulus
}

\author{
Boonthum Wongchai \\ Department of Mechanical Engineering, \\ Faculty of Engineering at Si Racha, Kasetsart University, Thailand
}

\begin{abstract}
Problem statement: Young's modulus and interfragmentary strain $\left(\varepsilon_{\mathrm{IF}}\right)$ are the important parameters in bone-plate testing and design. But Young's modulus is not suitable when we use with $\varepsilon_{\mathrm{IF}}$ in the bone-plate testing. Approach: This research proposed a study on the Interfragmentary Modulus (IM) as the new parameter for the bone-plate testing. Results: The results from the FEM show that the relations of the interfragmentary stress $\left(\sigma_{\mathrm{IF}}\right)$ and interfragmentary strain are linear for all cases with the condition of the DCP and the screws material properties are linear and isotropic materials. Conclusion: IM are the constant values and we can use IM in the bone-plate testing.
\end{abstract}

Key words: Interfragmentary modulus, interfragmentary strain, interfragmentary stress, dynamic compression plate, bone fracture

\section{INTRODUCTION}

The femur fracture occurs frequently that can be caused due to falls or accidents. When the body weight transmits to the femur, the maximum bending moments occur at the middle points of the femur. This point is the critical points of the bone fracture.

The bone-plate is commonly used in a human bone fracture and an animal bone fracture. There are a lot of researches that use the bone plate in rabbit to study the results or the side effects before using in human (Sharifi et al., 2009; Sadi et al., 2010).

There are various types of the bone plate, the Dynamic Compression Plate (DCP), the Locking Compression Plate (LCP) and etc. The DCP and the fractured femur are fixed by using the conventional screws. The compression force between the DCP and the femur is occurred because the conventional screw cannot lock with the DCP hole (Kanchanomai et al., 2008; Field et al., 2004). The LCP hole is developed to solve this problem. We can use both types of screw whit the LCP hole, the locking screw and the conventional screw. The distance between the fractured femur and the LCP can generate when using the locking screw and the compression force can generate when using the conventional screw (Miller and Goswami, 2007; Stoffel et al., 2003).

When the fracture occurs at the middle part of the femur, the physician will cut the fracture and form a gap of 1-10 mm.

Interfragmentary strain $\left(\varepsilon_{\mathrm{IF}}\right)$ is the important parameter of bone healing (Perren, 1979; Comiskey et al., 2010). Interfragmentary strain is defined as the ratio of the fracture gap displacement after the body load applied and the original fracture gap length as show in Fig. 1.

The Eq. 1 of $\varepsilon_{\mathrm{IF}}$ is:

$\varepsilon_{\mathrm{IF}}=\frac{\Delta \mathrm{L}}{\mathrm{L}}$

Where:

$\Delta \mathrm{L}=$ The displacement after the body load $\mathrm{W}$ applied

$\mathrm{L}=$ The original fracture gap length

The best $\varepsilon_{\mathrm{IF}}$ ranges from 2-10\% (Perren, 1979; Kim et al., 2010).

The DCP stress at the middle of the fracture site is the combine stress of the normal stress and the bending stress. The Eq. 2 of the normal stress is:

$\sigma=\frac{\mathrm{W}}{\mathrm{A}}$

Where:

$\sigma=$ Normal stress

$\mathrm{W}=$ Body load

$\mathrm{A}=$ Bone plate cross section area

The Eq. 3 of the bending stress is:

$\sigma_{\mathrm{b}}=\frac{\mathrm{My}}{\mathrm{I}}$

Where: 
$\mathrm{M}=$ Bending moment $=\mathrm{We}(\mathrm{e}=$ distance from the body load to the centroid of the DCP cross section area)

$\sigma_{\mathrm{b}}=$ Bending stress

$\mathrm{y}=$ The distance from the centoid of the DCP cross section area

I = Moment of inertia of the DCP cross section area

There are a lot of research that study for the boneplate testing by apply the load $\mathrm{W}$ at the femur head and fix the lowest of the femur (Ahmad et al., 2007; Kanchanomai et al., 2008). The fracture gab displacement can measure by using the displacement sensor. The DCP strain at the middle of the fracture site can measure by using the strain gauge and finally we can determine the stress by using the equation of the stress-strain relation.

Can we simplify the bone-plate testing? This is the main idea of this research. Similar the material testing only the applied force and the displacement have been measure and use for construct the graph of stress-strain relation. Young's modulus (E) is the slope of graph when tested material is linear material. The Eq. 4 of stress and strain is:

$\sigma=\mathrm{E} \varepsilon$

We can set up the standard test of the bone-plates for femur, tibia and etc. This idea will suitable for the bone-plate design in the future

The Eq. 2 is redefined as the interfragmentary stress $\left(\sigma_{\mathrm{IF}}\right)$ because only the body load act only boneplate cross section area at the fracture site.

IF the graph of $\sigma_{\mathrm{IF}}$ versus $\varepsilon_{\mathrm{IF}}$ is linear. The equation of Infragmentary Modulus (IM) is the slope of the graph. The Eq. 5 of $\sigma_{\mathrm{IF}}$ and $\varepsilon_{\mathrm{IF}}$ is:

$\sigma_{\mathrm{IF}}=\mathrm{IM} \varepsilon_{\mathrm{IF}}+\mathrm{k}$

where, $\mathrm{k}$ is constant value.

\section{MATERIALS AND METHODS}

Finite Element Analysis (FEA): The third generation femur of Pacific Research Lab, the 14-hole DCP and the 12 screws are assembled by using Solid Works 2007 as show in Fig. 1 and 2. The Pacific Research Laboratories bone models are usually used in biomechanics research (Stoffel et al., 2003). The assembled model is imported to MSC. Patran 2008 for construct the finite element model. The 4-node tetrahedral is used.

Material properties: The DCP and the screws are made of metals such as Stainless Steel (SS) and titanium alloys (Ti) are commonly used to treat bone fractures (Fouad, 2011; Kim et al., 2010).

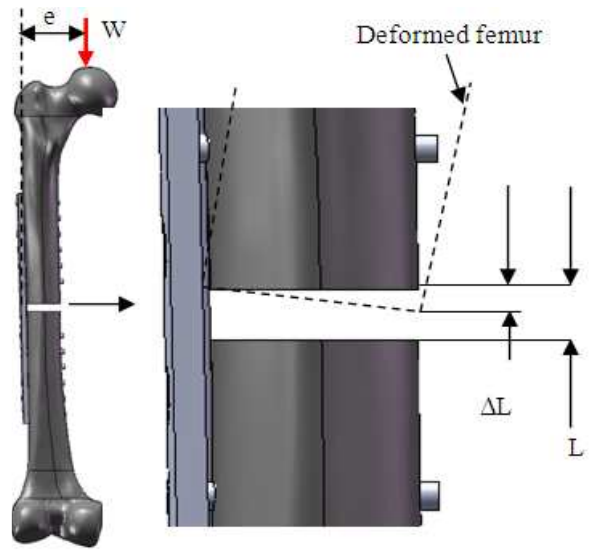

Fig. 1: The deformation of the fractured femur

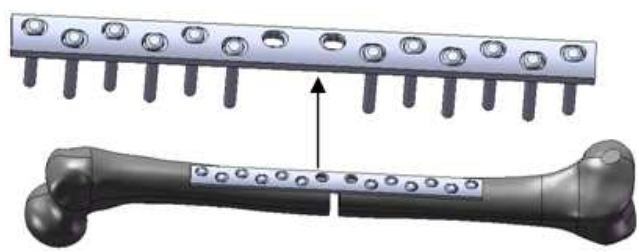

Fig. 2: The femur, DCP and screw assembly

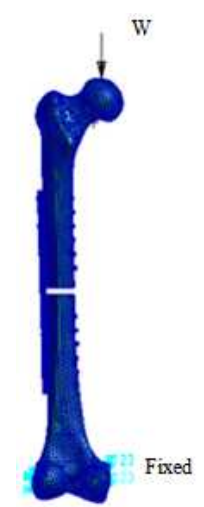

Fig. 3: Boundary condition of the FEM model

Table 1: Material properties

\begin{tabular}{lcl}
\multicolumn{2}{l}{ Table 1: Material properties } \\
\hline & Young's modulus $(\mathrm{GPa})$ & Poission's ratio \\
\hline SS & 193.0 & 0.3 \\
$\mathrm{Ti}$ & 193.0 & 0.3 \\
Cortical bone & 17.0 & 0.3 \\
Cancelous bone & 0.7 & 0.2 \\
\hline
\end{tabular}

Table 2: The contact surface types

\begin{tabular}{lll}
\hline Surface 1 & Surface2 & Type \\
\hline DCP & Screw & Glue \\
DCP & Cortical bone & Touch \\
Screw & Cortical bone & Glue \\
Screw & Cancelous bone & Glue \\
cortical femur & Cancelous bone & Glue \\
\hline
\end{tabular}


SS and Ti are used for study the effect of changing the material properties. The material properties of $\mathrm{SS}, \mathrm{Ti}$, cortical bone and cancelous bone are shown in Table 1 (Fouad, 2011; Stoffel et al., 2003).

Boundary condition: We apply the body load W of 50 $\mathrm{N}, 100 \mathrm{~N}, 150 \mathrm{~N}, 200 \mathrm{~N}, 250 \mathrm{~N}, 300 \mathrm{~N}, 350 \mathrm{~N}, 400 \mathrm{~N}$, $450 \mathrm{~N}$ and $500 \mathrm{~N}$ at the femur head. The fracture gab Length (L) is $10 \mathrm{~mm}$. Fixed displacement condition is applied at the lowest of the femur in finite element model as show in Fig. 3. The contact surface types are show in Table 2.

The finite element models from MSC. Patran 2008 r1 are solved by MSC. Marc for nonlinear finite element problems.

\section{RESULTS}

The displacement of the femur from FEA is shown in Fig. 4. The result of $\Delta \mathrm{L}, \sigma_{\mathrm{IF}}$ and $\varepsilon_{\mathrm{IF}}$ are shown in Table 3 and 4.

From Fig. 5 and 6 we can determine the equations of $\sigma_{\mathrm{IF}}$ and $\varepsilon_{\mathrm{IF}}$. The graph slopes is the values of IM as show in Table 5.

By eliminating the last constant terms of the $\sigma_{\mathrm{IF}}$ and $\varepsilon_{\mathrm{IF}}$ equations in Table 5 we can reconstruction the $\sigma_{\mathrm{IF}}$ and $\varepsilon_{\mathrm{IF}}$ equations as shown in Table 6.
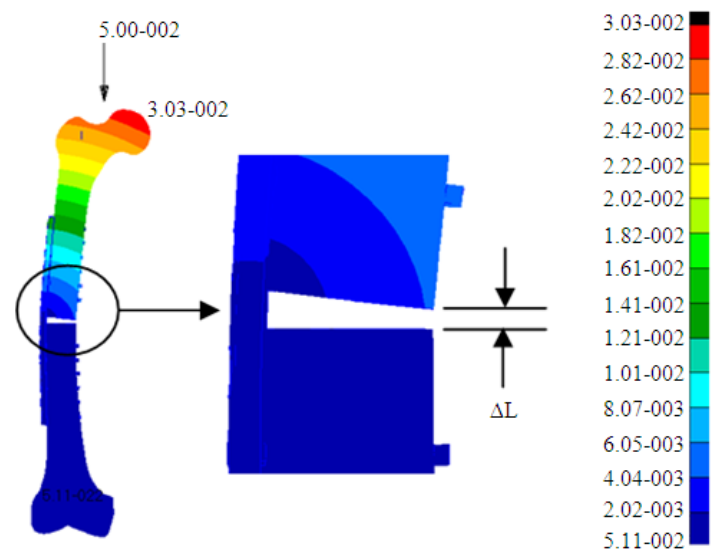

Fig. 4: The displacement of the femur

Table 3: The results of $\Delta \mathrm{L}, \sigma_{\mathrm{IF}}$ and $\varepsilon_{\mathrm{IF}}$ (DCP and screws are made of Ti)

\begin{tabular}{llll}
\hline $\mathrm{W}(\mathrm{N})$ & $\Delta \mathrm{L}(\mathrm{mm})$ & $\sigma_{\mathrm{IF}}(\mathrm{MPa})$ & $\varepsilon_{\mathrm{IF}}$ \\
\hline 50 & 0.617 & 0.67 & 0.0617 \\
100 & 1.218 & 1.34 & 0.1218 \\
150 & 2.133 & 2.01 & 0.2133 \\
200 & 3.013 & 2.68 & 0.3013 \\
250 & 3.794 & 3.35 & 0.3794 \\
300 & 4.335 & 4.02 & 0.4335 \\
350 & 4.936 & 4.69 & 0.4936 \\
400 & 5.530 & 5.36 & 0.5530 \\
450 & 6.144 & 6.03 & 0.6144 \\
500 & 6.746 & 6.70 & 0.6746 \\
\hline
\end{tabular}

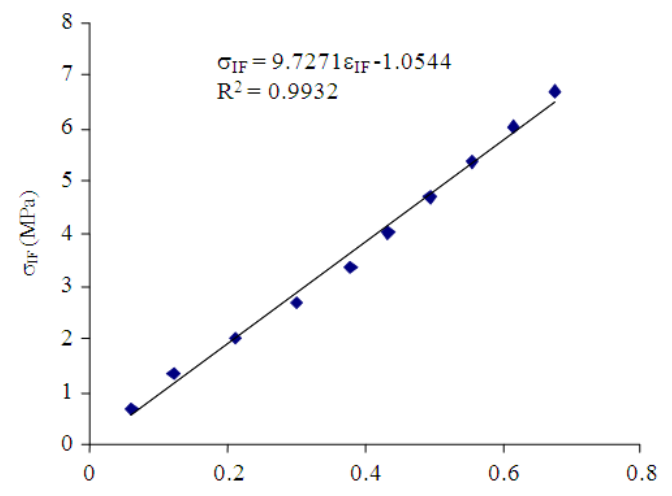

Fig. 5: The $\sigma_{\mathrm{IF}}$ and $\varepsilon_{\mathrm{IF}}$ curve fitting (DCP and screws are made of $\mathrm{Ti}$ )

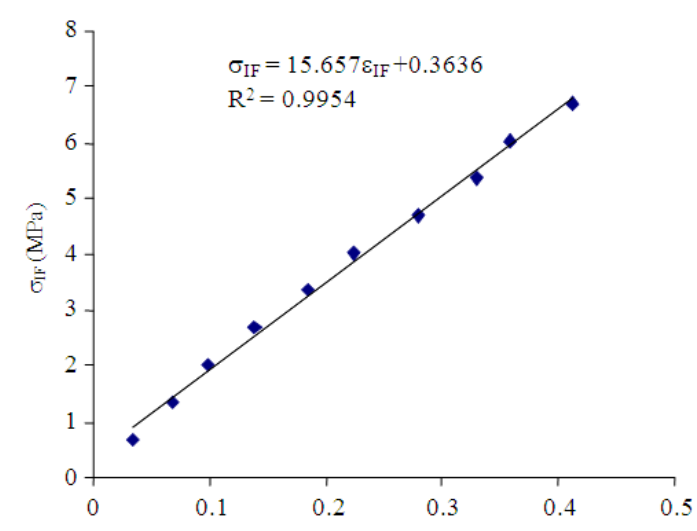

Fig. 6: The $\sigma_{\mathrm{IF}}$ and $\varepsilon_{\mathrm{IF}}$ curve fitting (DCP and screws are made of SS)

\begin{tabular}{llll}
\multicolumn{4}{l}{ Table 4: The results of $\Delta \mathrm{L}, \sigma_{\mathrm{IF}}$ and $\varepsilon_{\mathrm{IF}}$ (DCP and screws are made of SS) } \\
\hline $\mathrm{W}(\mathrm{N})$ & $\Delta \mathrm{L}(\mathrm{mm})$ & $\sigma_{\mathrm{IF}}(\mathrm{MPa})$ & $\varepsilon_{\mathrm{IF}}$ \\
\hline 50 & 0.346 & 0.67 & 0.0346 \\
100 & 0.674 & 1.34 & 0.0674 \\
150 & 0.985 & 2.01 & 0.0984 \\
200 & 1.380 & 2.68 & 0.1380 \\
250 & 1.846 & 3.35 & 0.1846 \\
300 & 2.229 & 4.02 & 0.2229 \\
350 & 2.791 & 4.69 & 0.2791 \\
400 & 3.290 & 5.36 & 0.3290 \\
450 & 3.585 & 6.03 & 0.3585 \\
500 & 4.103 & 6.70 & 0.4103 \\
\hline
\end{tabular}

Table 5: The equations of $\sigma_{\mathrm{IF}}$ and $\varepsilon_{\mathrm{IF}}$

\begin{tabular}{llc}
\hline Material & Equation of $\sigma_{\mathrm{IF}}$ and $\varepsilon_{\mathrm{IF}}$ & $\mathrm{IM}(\mathrm{MPa})$ \\
\hline $\mathrm{Ti}$ & $\sigma_{\mathrm{IF}}=9.7271 \varepsilon_{\mathrm{IF}}-0.0544$ & 9.7271 \\
$\mathrm{SS}$ & $\sigma_{\mathrm{IF}}=15.657 \varepsilon_{\mathrm{IF}}+0.3636$ & 15.6570 \\
\hline
\end{tabular}

Table 6: The new equations of $\sigma_{\mathrm{IF}}$ and $\varepsilon_{\mathrm{IF}}$

\begin{tabular}{llc}
\hline Material & Equation of $\sigma_{\mathrm{IF}}$ and $\varepsilon_{\mathrm{IF}}$ & $\mathrm{IM}(\mathrm{MPa})$ \\
\hline $\mathrm{Ti}$ & $\sigma_{\mathrm{IF}}=9.7271 \varepsilon_{\mathrm{IF}}$ & 9.7271 \\
$\mathrm{SS}$ & $\sigma_{\mathrm{IF}}=15.657 \varepsilon_{\mathrm{IF}}$ & 15.657 \\
\hline
\end{tabular}


Am. J. Applied Sci., 9 (3): 372-375, 2012

Table 7: The percentage error of the new equation (Ti)

\begin{tabular}{llll}
\hline$\varepsilon_{\mathrm{IF}}$ & $\sigma_{\mathrm{IF}}(\mathrm{MPa})$ & New $\sigma_{\mathrm{IF}}(\mathrm{MPa})$ & $\%$ err \\
\hline 0.1 & 0.92 & 0.97 & 5.92 \\
0.2 & 1.89 & 1.95 & 2.88 \\
0.3 & 2.86 & 2.92 & 1.90 \\
0.4 & 3.84 & 3.84 & 1.42 \\
0.5 & 4.84 & 4.86 & 1.13 \\
0.6 & 5.78 & 5.84 & 0.94 \\
0.7 & 6.75 & 6.81 & 0.81 \\
0.8 & 7.73 & 7.78 & 0.70 \\
0.9 & 8.70 & 8.75 & 0.63 \\
1.0 & 9.67 & 9.73 & 0.56 \\
\hline
\end{tabular}

Table 8: The percentage error of the new equation (SS)

\begin{tabular}{lccr}
$\varepsilon_{\mathrm{IF}}$ & $\sigma_{\mathrm{IF}}(\mathrm{MPa})$ & New $\sigma_{\mathrm{IF}}(\mathrm{MPa})$ & $\%$ err \\
\hline 0.1 & 1.93 & 1.57 & 18.75 \\
0.2 & 3.50 & 3.13 & 10.40 \\
0.3 & 5.06 & 4.70 & 7.18 \\
0.4 & 6.63 & 6.26 & 5.49 \\
0.5 & 8.19 & 7.83 & 4.44 \\
0.6 & 9.76 & 9.39 & 3.73 \\
0.7 & 11.32 & 10.96 & 3.21 \\
0.8 & 12.89 & 12.53 & 2.82 \\
0.9 & 14.45 & 14.09 & 2.52 \\
1.0 & 16.02 & 15.66 & 2.27 \\
\hline
\end{tabular}

The new equations have the percent error (\%err) as shown in Table 7 and 8.

\section{DISCUSSION}

The results of IM are constant values and the equations of $\sigma_{\mathrm{IF}}$ and $\varepsilon_{\mathrm{IF}}$ from the graph are linear equations. From the \%err of Ti material we can use IM similar the Young's modulus in the standard material testing, but \% error of SS material is unacceptable at low values of $\varepsilon_{\mathrm{IF}}$. The linear equation of $\sigma_{\mathrm{IF}}$ and $\varepsilon_{\mathrm{IF}}$ in Eq. 5 is suitable for the bone-plate testing more than Eq. 4 .

If we have more experimental of bone-plate testing in the future and use IM for standard bone-plate testing, IM will be the important parameter in biomechanics.

However, in this research used only linear and isotropic material ( $\mathrm{SS}$ and $\mathrm{Ti}$ ). The results in this research will be wrong if the bone-plate made of nonlinear material or anisotropic material.

\section{CONCLUSION}

IM are the constant values and we can use IM in the bone-plate testing.

\section{REFERENCES}

Ahmad, M., R. Nanda, A.S. Bajwa, J. Candl-Couto and S. Green et al., 2007. Biomechanical testing of the locking compression plate: When does the distance between bone and implant significantly reduce construct stability? Injury 38: 358-364. DOI: 10.1016/j.injury.2006.08.058
Comiskey, D.P., B.J. MacDonald, W.T. McCartney, K. Synnott and J. O'Byrne, 2010. The role of interfragmentary strain on the rate of bone healinga new interpretation and mathematical model. J. Biomech., 43: 2830-2834. DOI: 10.1016/j.jbiomech.2010.06.016 PMID: 20655536

Field, J.R., R., Edmonds-Wilson and R.M., Stanley. 2004. An evaluation of interface contact profiles in two low contact bone plates. Injury, 35: 551-556. DOI: 10.1016/S0020-1383(03)00215-8

Fouad, H., 2011. Assessment of function-graded materials as fracture fixation bone-plates under combined loading conditions using finite element modelling. Med. Eng. Phys., 33: 456-463. DOI: 10.1016/j.medengphy.2010.11.013 PMID: 21146439

Kanchanomai, C., V. Phiphobmongkol and P. Muanjn, 2008. Fatigue failure of an orthopedic implant-a locking compression plate. Eng. Failure Anal., 15: 521-530. DOI: 10.1016/j.engfailanal.2007.04.001

Kim, S.H., S.H. Chang and H.J. Jung, 2010. The finite element analysis of a fractured tibia applied by composite bone plates considering contact conditions and time-varying properties of curing tissues. Comp. Struct., 92: 2109-2118. DOI: 10.1016/j.compstruct.2009.09.051

Miller, D.L. and T. Goswami, 2007. A review of locking compression plate biomechanics and their advantages as internal fixators in fracture healing. Clin. Biomech., 22: 1049-1062. DOI: 10.1016/j.clinbiomech.2007.08.004 PMID: 17904257

Perren, S.M., 1979. Physical and biological aspects of fracture healing with special reference to internal fixation. Clin. Orthop. Relat. Res. PMID: 376198

Sharifi, D., S. Soroori, S. Hasaraki and N. Jafari, 2009. Radiographic evaluations of the tetra-calcium phosphate and diacalcium phosphate with bone plate in osseo-integration of bone repair in rabbit. Am. J. Anim. Vet. Sci., 4: 80-84. DOI: 10.3844/ajavsp.2009.80.84

Sadi, F., A. Veshkini, D. Sharifi and M.N. Masouleh, 2010. Ultrasonography and radiography evaluation of the cartilage graft in repair of experimentally induced radial bone defect in rabbit. Am. J. Anim. Vet. Sci., 5: 40-44. DOI: 10.3844/ajavsp.2010.40.44

Stoffel, K., U. Dieter, G. Stachowiak, A. Gachter and M.S. Kuster, 2003. Biomechanical testing of the LCP--how can stability in locked internal fixators be controlled?. Injury, 34: B11-B19. PMID: 14580982 